\title{
Exploring the Relationship Between Work-Famly Conflict \& Perceived Organizational Support on Project Commitment
}

\author{
Syeda Hira Hussain \\ Szabist, Islamabad, Pakistan
}

\begin{abstract}
This study aims to test the effects of work-family conflict and perceived organizational support on project commitment among project managers of construction industry. The recent growth in construction industry in Pakistan is booming, as many of the international market players have now come into the market. A cross-sectional study was conducted on 179 currently working project managers (middle managers and lead managers) with in the twin cities of Pakistan. Non-probability convinces sampling technique is used; data was collected by using questionnaires. This study is focused on the dimension of project commitment and variables effect on them; workfamily conflict shows negative effect and to maintain the imbalance situation and other hand perceived organizational support show positive relationship. This support helps employees to work with enthusiasm. Role theory has been used to support our $\mathrm{H} 1$ and organizational support theory to support hypothesis $\mathrm{H} 2$. The overall result of this paper is accepted significantly and further explains the relationship between these variables. Also, it would be constructive to examine other variables mediating and moderating impact on these variables such as family and spouse support and burnout. Further, the outcome related variables can also be tested on project managers of other industries.
\end{abstract}

Keywords: Work-family conflict, Perceived organizational support, Project commitment.

DOI: $10.7176 / \mathrm{EJBM} / 12-28-05$

Publication date:October $31^{\text {st }} 2020$

\section{Introduction}

The Pakistani construction industry has always been of economic and socially important to the country. In different prospective portion of Pakistani construction in the local and global market, conversely the construction has been covered the larger area of the market (Khan, 2015). The housing and construction sector in Pakistan plays an important role in developing economy and reducing economy. It delivers significant employment opportunities as it contributes through an advanced multiple effects with a host of favorable forward and backward connection with the economy (Hillebrandt, 1985).

The success and failure of every business around the world depends upon the commitment of the employee engagement within the organization, the relationship between the work family conflict and perceived organizational support are opposite in nature (Greenhaus, 1985; Bowen \& Govender, 2017). Work family conflict is the two-way conflict between the work family conflict (WFC) and family work conflict (FWF), which takes your commitment and understanding of the situations towards a negative side of performance (Xiaoyu Yu, 2020). The stress situation between family and work affects work performance and commitment, which further affects balance of life. On the other hand, perceived organization support (PSO) employers common values, employee's loyalty and dedication. Employees who are emotionally committed to their work demonstrate higher commitment towards work, optimum performance, less offs and less-ends likelihood of quitting their jobs (Kim, 2017). Generally, employees are concerned with their organizational commitment with them being valued by organization really helps them towards benefits and rewards. The main point of this research paper is project commitment (PC), how much employees are putting their effort towards work or project goal (Wang \& Armstrong, 2004). Commitment includes emotional attachment of employees to the organization with a willingness of the individuals to identify the organizational aims regardless of the situation. In all the elements of the work the most problematic element is the lack of commitment. Commitment play vital role in the success of the project (Gurbuz, 2013).

\section{Theoretical Background And Literature Review}

Literature review explains the relationship between the work-family conflict, perceived organizational support and project commitment. These are the factors that affect the project productivity and overall performance of the projects.

\subsection{Work-family Conflict and Project Commitment}

Work family conflict is called as "role conflict of the person when occurs then the person tried to complete his dual responsibility such as working as mother or father" (Dubrin, 1991). As per research review this term "Workfamily conflict" is seeing as a form of the inter-conflict, in which by pressurizing individual to maintain the balance between both works and home (Greenhaus, 1985). This type of situation is tested under two conditions, workfamily conflict (WFC) and family-work conflict (FWC). The prime aspect of work-family conflict usually occurs 
when it comes to maintain the balance between these two aspects, it's not that easy. Firstly the job related matters intercoms with the deed of family related duties by the person (Nart \& Batur, 2014). On other hand, second aspect is family-work conflict, which happens when the individual cannot maintain his/her work responsibilities. Both have their different priority levels, individuals work hard and harder to balance life in a better manner at home but for this balance, work takes a portion of the family time and this leads to work family conflict (Hakanen, 2008). In simple words, when an employee is not able to maintain a balance between their work and family. The reason is that discernment between WFC and FWC are usually seen when different factors get into this dispute with each other and earlier studies have emphasized that there is a significant correlation between these roles (Nart \& Batur, 2014).

In 1964, role theory which says that the form of inter-conflict in which role pressure is applied between the work and family domains are mutually clashing. Such pressure indicates that the participation of the work-role is made harder in the family-role and vice-versa (Aminah A, 2008).

Commitment refers to the "one's side involvement", willingness to agree with the decision, trying their level best to carry out their responsibilities is one's commitment. As distinguished, project commitment is characterized by the person willingness, acceptance of organization goal, assurance towards their project and taking the relationship further (Hoegl, 2006). Goal commitment is aligned with project commitment which depends on member's acceptance, involvement and sustaining the relationship with the project team.

The relationship between these two variables are more towards negative association because work-family conflict creates imbalance between the individuals work life and home life, project commitment demands all the hard works towards achieving project goal (Kyle \& Peter, 2013).

$\mathrm{H} 1$ : Work-family conflict had a negative relationship on project commitment.

\subsection{Perceived Organizational Support and Project Commitment}

Modern organizational situation becomes more varied and complex, perceived organizational support (PSO) refers to, employee's perceptions where organization highly thinks about their employee's needs and welfare and act accordingly (Eisenberger, 1986). This explains the mutual understanding between employee's and the organization as social exchange theory and the norms of reciprocity. Organizational support theory says the mutual understanding between the employees and the organization then, employees feels inner obligation to exchange supportive and favorable behavior towards their organization aim (Eisenberger, 2011). Further POS also cover socio-economic needs of the employees (e.g. need for appreciation), which leads into favorable condition for the employees.

Accordingly, POS is positively related to the many of the term job satisfaction, job performance, positive attitude, and work-environment. Some of the papers even state that the POS decrease the employee's turnover intentions, burnout and absentees (Kurtesis, 2017). Previous studies state that POS helps in creating positive attitude and decrease conflict.

Most of the literature on the commitment examines project commitment. Project commitment is defined as the bond between the individual and their project team. Commonly studied commitment is (affirmative commitment) which explains the relative efforts of the individuals involvement into their goal of the project (Caesens, 2016). Commitment can be carried out when the employees and project have some goal or both parties are gaining positive outcome (rewards or completed project).

Commitment to the project or the organization is the greatest challenge for the project manager and it's important to the functionally team. The successful projects managers develop commitment through supportive and innovative behaviour. Construction related project commitment and focusing on what is important for project by revising your work which leads to successful project and then to rewards (Gaetane, 2019).

The relationships between these two variables are positively associated with another. POS creates balance between the work lives which leads project towards success; project commitment wants all the hard works towards achieving project goal.

H2: Perceived organizational support had a positive relationship on project commitment.

\subsection{Research Framework}

The research model for this study is made-up with the help of role theory (1964) and organizational support theory. Under these theories, the stress in the form of work-family conflict which leads you to extreme stress and this turn in creating problem in lives and other one; supporting employee is the key of successful project. Research aimed on to find out that how the conflict between work and life affects the satisfaction of an employee both at work and in personal life. Based on this; the research model is figure 1.

\subsection{Model}

The model explains that the work-family conflict and perceived organizational support are (independent variable) and they are affecting on project commitment (dependent variable). According to our hypotheses work-family 
conflict has negative and perceive organizational support has positive effect on project commitment.

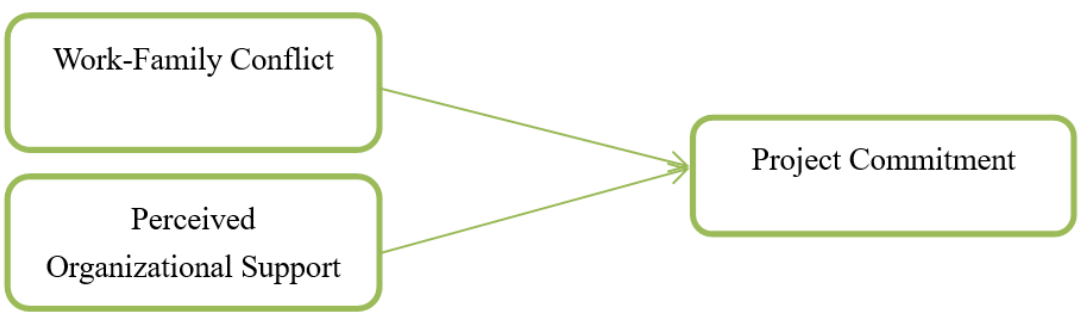

Figure 1

\section{Methodology}

The research study opted for this research is descriptive approach. Data were collected through random sampling by questionnaire. Questionnaires were delivered between project managers and team members of the project of the construction industry. Based on geographical area twin cities (Islamabad and Rawalpindi) of Pakistan, 200 (project managers and individuals who were into same project) were selected from twin cities. Especially those project managers who are currently working into projects nowadays because they require demanding work schedule to balance the time at home. Then the data were collected from 179 project managers, middle managers, resulting the total response were $89.5 \%$.

To measure the work-family conflict, the (Carslon, 2000) and (Stehpens and Sommer, 1996) WFC scale with 10-items was adopted. The sample items includes; 'my work keeps me from my family activities more than I would like"; " the time I must devote to my job keeps me from participating equally in household responsibilities and activities".

Perceived organizational support was measured by the, (Eisenberger et al 1997, 2001). POS scale with 7 items was adopted. The sample includes; 'help is available from my organization when I have a problems supporting the elderly and children", 'my organization really care about my well-being"'.

To measure the project commitment the dependent variable of the research, (Blau G, 1985) was adopted with 5-items. The sample includes; ' I want the career I am doing now', “'if could do it all over, I will still choose my same career',

The respondent rate for each statement were tested on 1-5 point Likert scale (Rensis L, 1932), where 1 indicates "not significant" and a score of 5 indicates "'always significant".

The demographic values of project manager are on gender, age, salary (in month), marital status, number of children, experience in work are measured while analysis. Since after this significant result are reported from previous studies. For conducting results IBM SPSS were used to measure frequencies distribution, testing hypotheses, reliability analysis, regression and correlation.

\section{Results}

After running the test both of the hypotheses are accepted. Following are the details.

\subsection{Descriptive Statistics}

The respondent demographical characteristic includes age, gender, qualification, experience, role of respondent, number of response. The demographical characteristics of 179 respondents are measured with percentage $(\%)$ analysis. The result of age from $18-25$ years is $(26.8 \%), 26-35$ years is $(36.3 \%)$, and 36-45 years is $(20.2 \%)$ and 46-above is (16.7\%). The respondent on gender are 134 male $(74.8 \%)$ and 45 female $(25.2 \%)$.

Regarding the qualification the from bachelors to other education. Following are; bachelors are $99(55.3 \%)$, masters are $64(35.8 \%)$, PhD's are $12(6.7 \%)$ and other education is $4(2.2 \%)$. The next frequency distribution is about experience in construction industry; from 0-3 years are $80(44.7 \%), 3-5$ years are $23(12.8 \%), 5-7$ years are $26(14.6 \%)$ and 8-above years are $50(27.9 \%)$. And total 200 questionnaires were delivered between the project managers, 179 were used for running test and remaining was uncompleted, so I didn't use them.

Descriptive Statistics

\begin{tabular}{|l|r|r|r|r|r|r|r|r|r|}
\hline \multirow{2}{*}{} & \multicolumn{1}{|c|}{$\mathrm{N}$} & \multicolumn{1}{c|}{ Minimum } & Maximum & \multicolumn{1}{c|}{ Mean } & \multicolumn{1}{c|}{ Std. Deviation } & \multicolumn{2}{|c|}{ Skewness } & \multicolumn{2}{c|}{ Kurtosis } \\
\cline { 2 - 9 } & Statistic & \multicolumn{1}{c|}{ Statistic } & \multicolumn{1}{c|}{ Statistic } & Statistic & \multicolumn{1}{c|}{ Statistic } & Statistic & Std. Error & Statistic & Std. Error \\
\hline WFC & 179 & 1.00 & 4.10 & 2.7268 & .59479 & -.115 & .182 & .132 & .361 \\
PC & 179 & 1.00 & 5.00 & 2.9777 & .75219 & -.090 & .182 & -.243 & .361 \\
PSO & 179 & 1.00 & 4.86 & 2.8220 & .70355 & .132 & .182 & .685 & .361 \\
Valid N (listwise) & 179 & & & & & & & \\
\hline
\end{tabular}

Table 1

Table shows that all the values lays under 1-5, standard deviation deviance from mean value of the data. 
Skewness and kurtosis are used to check the normality of the data and skewness values lays between $(+1$ to -1$)$ and in this table all the values are in predefined range.

Furthermore reliability test, correlation analysis and regression analysis are performed. Reliability tests have been performed to check the consistency of the questionnaires, it is important to check the reliabity and validity of the paper. If the paper value lies under Cronbach's Alpha value (0.7) this test was performed on IBM SPSS and tests are; work-family conflicts have 10 items and Cronbach's Alpha is (.798), perceived organizational support is (.850) and project commitment is (.748). These all values show that variables are reliable and satisfactory.

Correlation analysis/tests were performed to see the relationship between the variables, this analysis show that the either independent having significant relationship with dependent variable or not. The correlation between the work-family conflict and project commitment is negative and our hypotheses demand this and as per second hypothesis perceived organizational support having positive relationship with our dependent variable. As per research both hypotheses are accepted and significant.

Regression analysis usually performed to check either, the hypothesis is accepted or rejected. Regression analysis is performed on all variables.

- Work-family conflict having negative effect on project commitment and there beta value is (.273) so one unit change in work family conflict effect $(.273)$ change in project commitment.

- Perceived organizational support having positive effect on project commitment and there beta value is (.374).

The tests show value of R-square is . 170 so, our independent variables are having $17 \%$ deviation on dependent variable, which is significant. The value of t-statistics is, for work-family conflict is 3.149 and perceived organizational support is 5.094 respectively. Values are bigger than the benchmark (1.96) and both of hypotheses are accepted.

Further, after running all the tests both of our hypotheses are accepted. Data were collected through questionnaires and they were sending to project managers and other team members such as (lead manager and middle manager). Results emphasized that work-family conflicts has negative effect on project commitment and perceived organizational support has positive effect on project commitment.

\section{Discussion}

Construction is the complex industry; it requires commitment, accuracy, hard work and a lot of work and still this industry is rising rapidly. It is stated that construction industry is linked with the strong linkages of the economy. Results supported the hypotheses; H1 was about the negative effect of work-family conflict on project commitment, work-family conflict is the very trending topic nowadays because either you are teacher, doctor or take any name this variable is commonly faced by the individual because maintaining the balance between the work-life and home-life is the basic agenda of any individual and project commitment how much you are into your project and his related responsibility so while interviewing one of the project manager of the construction site, he said it's tough to maintain balance; there is so much hustle sometimes when I required my many peoples at different place but still trying hard to manage this on the other hand project is in my hand but every individual other here works for his family.

Further, H2 was about on the perceived organizational support impact on project commitment and they have significantly positive relationship with each other. Perceived organizational support is about how much your organization support you, supporting organization and project-based organization played vital role into the life of employees; when they understand employees needs and problem then employee turn more towards there organization and then he puts more heart into the work and by doing this employee show more commitment and responsibility towards their project.

\section{Limitation And Implications}

This study adds to the existing information on work-family conflict, perceived organizational support and on project commitment. Data gathered by using pervious research, project commitment the main variable; individual has to perform his duty with the proper responsibility and supporting organizations help employees to work harder. Supporting your employee and solving his problem help him to maintain balance between the work place so employee doesn't have to carry the conflict between the work-life and home-life.

It is certain to admit the limitation of the present study. Following are the few limitations; I have done crosssectional survey on this study, data was collected at the one point at time and conclusion was obtained by this survey. Data on work-family conflict, perceived organizational support and project commitment were gathered at one point of time. Thus, for future work longitudinal study can be performed on this model; to get to know the more variation into results.

While conducting the survey, many of respondent were saying that they face emotional exhaustion, depression while managing both lives. So as per my view; for future limitation we should add burnout as a mediator between work-family and project commitment. To acknowledge the more variations and other side of the picture. 
Since the work-family conflict roles relays on both individual home or on individual work place and there support matters a lots, so we can add family support/spouse support as a moderator into this model to gain more clear picture of this model.

\section{Conclusion}

Construction is the wider industry and grower faster; as this is going in there in rapid pace towards successful project, some other problem came across between them. The mostly used variable is work-family conflict; the imbalance between the lives of work and home. Perceived organizational support is supported by the organization; either its organization or project team the support really comfort the employee and this help to maintain better commitment to work. I have done survey in the twin cities of Pakistan, data were gathered through cross-sectional study by questionnaires. Role theory is used in first hypothesis inner role pressure create more chaos into lives and organizational supporting theory is for second hypothesis. This study proves that employees had to face many of problems to manage the lives and supporting organizations create more way towards success. This model with one positive and negative hypothesis is about the commitment towards your work life and home life.

\section{References}

A, A. (2008). "Project Management Trends of Pakistani IT Industry. IEEE Trans on Engineering Management, $117-123$.

Batur, N. \&. (2014). . The relation between work-family conflict, job stress, organizational commitment and job performance: A study on Turkish primary teachers. European Journal of Research on Education, 2(2), , $72-$ 81.

Bowen, P., \& Govender, R. (2017). Work-related contact, work-family conflict, psychological distress and sleep problems experienced by construction professionals: An integrated explanatory model. Bowen, P.; Govender, R.; Edwards, P.; Cattell, K. Work-related contact, work-family conflict, psychological distress and slee Constr. Manag. Econ., 153-174.

Caesens. (2016). . Therelationship between perceived organizational support and proactive behaviour directed towards the organization. Eur. J. Work Organ. Psychol. 25, 398-411.

Carlson. (2000). .Construction and initial validation of amultidimensional measure of work-family conflict. $J$. Vocat. Behav., 249-276.

Dubrin. (1991). Comparison of the job satisfaction and productivity of telecommuters versus in-house employees: A research note on work in progress. Psychological Reports, 68(3_suppl), 1223-1234.

Eisenberger. (1997). Perceivedorganizationalsupport,discretionarytreatment, and job satisfaction. . J. Appl. Psychol. 82, 812-820.

Eisenberger. (2011). Perceived FosteringenthusiasticandProductiveEmployees. Washington.

Eisenberger, R., \& Armeli, S. (2001). Reciprocation of perceived organizational support. . J. Appl. Psychol, 4251.

Eisengerge. (1986). Perceived organizational support. . J. Appl. Psychol. 71,, 500-507.

G, B. (1985). The measurement and prediction of career commitment. J. Occup. Psychol. 58, 277-288.

Gaetane. (2019). Perceived Organizational Support and Workplace conflict: Mediating role of Failure related Trust . Psychological Sciences Research Institute.

Greenhaus, J. (1985). Sources of conflict between work and family roles, Academy of Management Review.

Gurbuz, S. T. (2013). The impact of perceived organizational support on work- family conflict: Does role overload have a mediating role? Economic and Industrial Democracy, 34(1), 145-160.

Hakanen. (2008). The Job Demands-Resources model: A three-year cross-lagged study of burnout, depression, commitment, and work engagement. Work \& Stress, 224-241.

Hillebrandt, P. (1985 ). Analysis of the British Construction Industry, Macmillan, London. .

Hoegl. (2006). Team goal commitment in innovative projects. . International Journal of Innovation Management, 10, 299-324.

Khan, R. A. (2005). Role of construction sector in econimics growth: empirial evidence from Pakistan economy. Advance and Integrating Contruction Reserach.

Kim, S. (2017). Perceived organizational support as a mediator between distributive justice and sports referees' job satisfaction and career commitment. Ann. Leis, 169-187.

Kurtesis. (2017). Perceived organizational support: a meta-analytic evaluation of organizational supporttheory. J.Manag.43, 1854-1884.

Peter, K. \&. (2013). Examining Project Commitment in Cross-Functional Teams: Antecedents and Relationship with Team Performance. Springer Science+Business Media New York .

Sommer, S. a. (1996). The measurement of work to family conflict. . Educ. Psychol. Meas 56, 475-486.

Wang, X., \& Armstrong, A. (2004). . An empirical study of PM professionals' commitment to their profession and 
employing organizations. . Int. J. Proj. Manag, 377-386.

Xiaoyu Yu, X. M. (2020). Exploring the relationship between entrepreneurial failure and conflict between work and family from the conservation of resources perspective. International Journal of Conflict Management. 